\title{
Development of strategies for the development of urban passenger transport in EurAsEC countries
}

\author{
Konstantin Andreev ${ }^{1, *}$, and Vyacheslav Terentyev ${ }^{1}$ \\ ${ }^{1}$ Ryazan State Agrotechnological University, 1, Kostychev Str., Ryazan, 390044, Russia
}

\begin{abstract}
Currently, in many cities of the Russian Federation and the EurAsEC countries, due to an increase in the level of motorization, there is an increase in traffic congestion, which leads to unproductive losses of time and an increase in transport costs in the economic sector. Therefore, urban infrastructure is currently unable to provide unhindered traffic flow. The scientific and practical purpose of the article is to summarize the best practices of transport planning of the urban route network in large cities of the Russian Federation, and integrate it in cities of the EurAsEC countries. The development of such projects occurs, as a rule, in several stages. The main stages are as it follows: 1) a survey of passenger flows on public road transport, 2) analysis of the data and development of measures to optimize the route network. Based on the task, an analysis is carried out of a survey of passenger flows (transport mobility of the population), stopping points and the intensity of public transport, including: general provisions and a methodology for conducting a survey of urban public passenger transport. The experience of foreign countries in the use of commercial organizations for urban passenger transport, in the organization of transport systems functioning, the definition and justification of the role of each type of transport (for the public and private sectors) is analyzed. The proposals on the development of interconnections and the functioning of various modes of transport are considered. Measures have been proposed to optimize the route network of urban passenger transport based on modeling in a macroscopic model, and quality standards for the provision of services and the introduction of navigation management systems aimed at improving the quality of public services have been determined.
\end{abstract}

\section{Introduction}

City transport is the most widespread type of passenger automobile transport. The main task of organizing and planning production in each motor transport enterprise is the rational combination and use of all production resources in order to perform maximum transport work and improve the quality of public services for passenger transportation. In order to solve the transport problem in any city successfully, organizational measures are necessary. City passenger public transport (hereinafter - the CPPT) is an essential element of the

\footnotetext{
*Corresponding author: kosta066@yandex.ru
} 
transport system, which provides daily transport mobility of two-thirds of the total population. The quality of life of the population of modern large cities (megacities) substantially depends on the efficiency of urban passenger transport management. The management of urban passenger transport has undergone significant changes since the transition to a market economy, which has had a significant impact on the financial condition of passenger enterprises and, as a result, on the level of quality of public transport services.

Currently, in many cities of the Russian Federation and the EurAsEC countries, due to an increase in the level of motorization, an increase in the labor and business activity of the population is observed and the need for visits to shopping centers, cultural and leisure facilities, and the need for trips outside the city are increasing. All this leads to a rapid increase in demand for movement both in quantity (volume of traffic flow) and in quality terms (comfort, safety and reliability of transport). Existing transport infrastructure and passenger transport do not satisfy the growing demand in full. Difficulties arise in the consistent planning of urban passenger transport systems and their management, which is a prerequisite for the successful solution of existing transport problems [1]. Urban infrastructure is currently unable to provide unhindered traffic flow, which leads to unproductive waste of time and increased transport costs in the economic sector [2].

\section{Passenger traffic survey (transport mobility of the population)}

Some surveys take place in order to identify passenger flows, distribute them in directions, collect data on changes in passenger flows over time. Existing passenger flow survey methods can be classified according to a number of criteria.

So, according to the length of the period covered, there are systematic and one-time examinations. Systematic examinations are carried out daily by linear workers of the service department during the entire period of movement. Short-term examinations for a particular program defined by goals are called one-time.

According to the width of the transport network, continuous and sample surveys are distinguished. Continuous surveys are carried out simultaneously over the entire transport network of the served community or region. Sample surveys are carried out for individual areas of movement, conflict points or certain routes in order to solve local, private, narrower and specific problems. The purpose of the survey is to determine the quantitative characteristics of passenger flows and transport mobility of the population, as well as obtain some baseline information for the modernization of the urban public passenger transport system in the city. The objectives of the survey are:

- inspection of passenger flows on all actually functioning public-service, as well as on the main commercial routes of CPPT;

- determination of quantitative characteristics of passenger flows;

- determination of the existing passenger flow on routes in the direction of bus movement, by time of day, on various days of the week;

- determination of occupancy for passenger buses in the direction of bus movement, by time of day, on various days of the week;

- analysis of doubling routes;

- processing the results of the passenger flow survey on the route.

The survey is conducted according to a specially developed technique adapted for this system of CPPT.

A survey of CPPT includes several activities:

1) development of a methodology for conducting a survey of CPPT; 
2) preliminary examination of stopping points and the formation of a database of these points;

3) full-scale inspection of passenger flows;

4) inspection of traffic intensity of commercial vehicles.

Inspection of passenger flows on routes is carried out by the tabulation method, which ensures $95 \%$ reliability of the received primary data from the calculation of the estimation of passenger traffic for each route at the stage of statistical processing.

The statistical processing of passenger flow survey materials is carried out on the basis of primary accounting data using computer technology and contains the following route characteristics:

- names of stopping points;

- distance of the route in sections;

- bus capacity utilization ratio;

- passenger turnover by the hours of the day on the route for each hour;

- passenger traffic in the forward and reverse directions on the route, transport work in the forward and reverse directions;

- total passenger traffic on the route;

- transport work on the route in the forward and reverse direction;

- number of vehicles and return trips on the route [3].

An analysis of the duplication of routes of the city passenger transport is necessary to assess the need to change existing route schemes and build proposals for a new route system. The tables provide data on duplication of routes by other functioning routes. For each route, the percentage of duplication is indicated. There are additional routes that have duplication of more than $70 \%$. Such routes are primarily targets for reviewing and reducing duplication in the updated route network.

As a result of the on-site examination, some filled-in passenger flow monitoring forms along the routes will be received. Data processing of these tables is carried out in a semiautomatic mode by scanning them and further computer recognition of their contents using specialized software. After that, the data is imported into the database. The presented method provides an acceleration of the processing of passenger traffic inspection results and facilitates filling out databases for the purpose of further analysis. The resulting database is used to build passenger flow diagrams, which are the dependences of the passenger flow on each route section from the time of day (vehicle operating time on the route). The diagrams are based on a sample survey of vehicles on the studied routes [4].

The main factor when choosing a route by a passenger is the total time that is spent on approaching a stop; waiting for transport, moving along the route; transfer, if required; as well as moving from a stop to your destination. This determines the efficiency of transport services for the population and the choice of this or that transport mode. Based on the foregoing, one can conclude that the efficiency of the city passenger transport depends on reducing the time spent on transportation, which will lead to an increase in the quality of public services and increase the comfort of transportation. To do this, "express routes" are used, which will provide high speed passenger transportation in the city passenger transport.

It is most expedient to use express routes in the morning and evening rush hours, when the passenger flow is as large as possible. Also, traffic should be organized in dedicated lanes for public transport, which will ensure traffic on schedule and increase the reliability of passenger delivery. All these factors will help reduce population fatigue, reduce economic losses and create a single transport space to satisfy passengers.

For an optimal assessment of the possibility of introducing express routes, it is necessary to be guided by the basic requirements: 
1) There should be steady pendulum correspondence from places of residence to places of employment;

2) The work of the enterprise should begin and end on schedule.

The advantage of such transportation is: scheduled traffic, high traffic performance, high passenger flow, regularity of traffic, high speed and environmental friendliness.

The survey results are compiled into a specialized electronic database, in which further processing and analysis of the data obtained is carried out to calibrate the computer model of the city passenger transport. The results of a study of the functioning of public passenger transport using mathematical modeling and experimental measurements on routes are necessary to create a development strategy and the subsequent modernization of the passenger transport system [5].

\section{The experience of foreign countries in the use of city passenger transport}

It is known that public transport plays a significant role in meeting the transport needs of the population, carrying out up to a quarter of the volume of passenger traffic [6]. It is noted that public transport plays a special role in large cities focused on this type of transport. There is practically no country having the share of public transport in the total volume of passenger transport greater than the share of an individual one. Nevertheless, everywhere the policy in the field of city passenger transport takes into account its social significance. The establishment of low fares or benefits is associated with the fact that public transport is used primarily by low-income passengers. Thus, the necessary social policy has led to the fact that already in almost all industrialized countries city public transport is becoming unprofitable.

The receipt of funds to maintain and develop city public passenger transport comes mainly from two sources: 1) the state; 2) regional and local authorities. In many countries, funds from individual business sectors, as well as loans and borrowings, are attracted. The budgets of developed countries as a basis have various kinds of taxes. These funds, in particular, are directed to subsidies that reimburse both capital costs and operating expenses. In Belgium and the Netherlands, the state traditionally provides subsidies for both types of costs of passenger transport. In France, Sweden, Great Britain, Switzerland, Canada, Denmark, the lion's share of subsidies is received by transport from regional and local authorities. In the USA, Italy, Austria and Germany there is a wide variety of receipts, both from federal and local authorities. At the same time, the state is mainly interested in subsidizing capital costs, and in most cases local and regional authorities cover current costs. At the same time, participation of both commercial and state-owned companies in the transport services market is ensured. In developing countries, CPPT is in its infancy and has not reached a stationary state. This leaves a certain imprint on the problems in the field of relations and participation at the market of transport enterprises of various forms of ownership. The character of the previous historical development of the society and the local national approach also impose additional restrictions. Thus, the EurAsEC countries have many common features, in particular, the presence of one or more large municipal transport companies in the city and many small commercial carriers. The degree of development of the latter largely depends on the policy of local (municipal) authorities. In many cities of the EurAsEC countries, private companies, due to insufficient level of development and cooperation, have rolling stock of small and especially small capacity, operate on the most profitable routes and double routes of the municipal transport [7].

Transport systems of various types differ in terms of passenger transportation convenience, efficiency of use, environmental impact, profitability and development. When deciding on the choice of an option for the development of city transport, three main factors 
should be taken into account: at the level of public interest (regional development, city development, the environment, economic efficiency of the option, the possibility of allocating capital investments); at the level of operational transport enterprises (traffic capacity, transport capacity of vehicles, management control, organization of work, operating costs); at the level of passengers' interests (minimum travel time, comfort, safety, transportation costs).

The volume of traffic, the level of service, tariffs, cost and productivity of transport services differ in different countries. These differences are the result of different strategies for the development of passenger transport, which is manifested in the choice of the objectives of its functioning, organization and management of transport systems, types and sources of financing, the degree and methods of attracting the private sector. For developed countries, the need for priority development of public transport has become apparent. Almost all countries of the world have encountered problems in functioning of the city passenger transport. An analysis of a number of scientific works showed that the reform in the field of city passenger transport systems abroad comes down to the following:

- reduction of government spending to maintain the city passenger transport;

- more complete satisfaction of demand for transportation with a decrease or moderate increase in fare;

- creation of conditions for the renewal of the park at the expense of the enterprises themselves;

- expansion of opportunities for local authorities to make necessary, but unpopular decisions (fare increase, cancellation of benefits, etc.).

An analysis of the experience of reforming city passenger transport abroad shows that the transition from a model of administrative regulation to models of a regulated market and deregulation has both positive and negative consequences. Positive results include a decrease in budget subsidies observed in all cities that are committed to the corresponding model. The negative consequences of the transition to these models include the emergence of social problems. Passengers lack confidence in the stability of the route network, they find it difficult to understand the working conditions of a large number of different companies, they experience difficulties in obtaining information about existing routes and conditions of transport service. The development of competition is accompanied by some reduction in the personnel of transport enterprises and a decrease in the level of wages.

In order to address many of the shortcomings in the privatization of city passenger transport in highly developed countries, the following measures were taken in the organization of the management of the CPPT:

- CPPT management bodies have been created that perform the functions of managing transport companies and enter into contracts with private firms for servicing pre-designed routes;

- the bodies of passenger self-government were created that perform the functions of organizing transportation, planning the development of the transport network, coordinating the work of various companies and various types of cargo transportation, monitoring trip operations and maintaining the quality of the transportation process;

- there has been some redistribution between firms according to the results of a comparative analysis of routes that are not profitable, but are necessary for society with the preservation of subsidies for these routes;

- subsidies from external sources of financing were kept when organizing transportation at preferential rates for organizing socially significant transportation, which is stipulated in the contract;

- there was a restriction on the size and nature of the interference of local authorities in the activities of the country's motor transport companies with the scope of the current law; 
- transport companies have made certain commitments to meet the need for transportation, vehicles, personnel;

- bus contracts were awarded based on tenders.

On the one hand, it is clear that public administration in the system of city passenger transport is necessary, since it is a strategic area of activity. At the same time, the following areas of regulation are taken into account: monitoring the activities of monopoly transport enterprises (antitrust laws should apply to urban passenger transport); control and, in many cases, restriction of the level of transport tariffs; introduction and control of common norms, standards and rules in the field of environmental protection, traffic safety, working conditions in transport, as well as common technical standards. On the other hand, the higher the level of development of city passenger transport, the more obvious that with limited budgetary resources, many tasks can be effectively solved by attracting private capital.

Thus, an analysis of foreign experience shows that regardless of the chosen model, administrations of all cities in the world are trying to pursue a policy of limiting the growth of budget subsidies and transportation tariffs. However, the choice of the model determines the means to achieve this goal.

Thus, the experience of foreign countries shows that market relations in the economy in no way preclude the creation of a developed and active system of multilateral state regulation of transport activity. Even in those developed countries where freedom of enterprise is considered as the main principle of functioning and development of the economy, transport activity is subject to constant and often quite strict regulation by the state, and the legality and necessity of the existence of such a system has long been recognized by both transporters and the public.

In most countries, the organization of the city passenger transport is the subject of constant attention and concern of the authorities, raising funds for its financing, including investment. The main goals in the field of city passenger transport include: providing each citizen with the possibility of exercising his rights to transport at affordable prices, including that for the poorest segments of the population, with a quality of service that meets relevant standards; increasing the stability of the functioning of the complex; reduction of harmful effects on the environment, improving traffic safety and reducing the loss of time for passengers to travel by improving the route network and timetables, roads; encouraging, the use of urban passenger transport instead of personal cars, especially in central urban areas.

For the development and achievement of such goals, mechanisms have been created for sustainable financing of city passenger transport, which makes it possible to raise the standards of quality of transport services and the level of safety, reduce the harmful effects on the environment, slow down the growth of tariffs, and expand privileges on travel.

Currently, in many cities there are four types of public transport: 1) a trolley bus; 2) a bus; 3 ) a minibus; 4) a taxi.

The first two are served most often by municipal organizations and operate by subsidizing budget expenditures, i.e. are utility companies. Many routes have significant overlap. The bulk of the rolling stock of enterprises is buses and trolleybuses. In reality, the situation is such that the release of rolling stock along many routes is much less than required, and in some cases more, that is unfortunately not always monitored by the authority controlling the transportation. Timetables are practically not respected, there is not only ticket control, but also the system itself. Also, drivers often pick up and drop off passengers outside established stopping points.

Minibuses transport a large part of the city's population and connect remote districts of the city. These routes are served by commercial firms. Routes are mainly laid so that duplication by minibuses of public transport routes is minimized. The comfort and safety of 
transportation is at a low level due to regular violation by the drivers of the road traffic regulations, poor technical condition of vehicles and, in general, due to the fact that most of the rolling stock of enterprises is represented by brands that are not intended for passenger transportation on regular city public routes of transport.

The so-called taxis are passenger vehicles of individuals, on which transportation is carried out along the most popular urban public transport routes. The license and other permits for the carriage of passengers on routes are most often absent. They carry out their activities due to the loyalty of the state automobile inspection service and corruption in this environment.

In general, the density of the route network of the city is high, and, as noted above, there is a relative separation of the spheres of influence of public and commercial vehicles. Utility routes run mainly along major highways, neighborhoods, industrial and business areas. Commercial routes cover almost all neighborhoods with different types of buildings, which gives a high density of the route network and provides good transport accessibility.

One of the features of the functioning of commercial transport routes is their fragmentation. So, for example, a certain route functions and it has two more abridged variants. As a rule, the full route and its service drives. There may be times when drivers arbitrarily drive along any of these three routes, as they are served by the same company.

On the foregoing, the following conclusions can be drawn about the functioning of the city public transport system:

1) there is no system for monitoring compliance with passenger transportation rules;

2) there is no system for monitoring compliance with traffic schedules and rationing the number of units of rolling stock for each route;

3 ) there is no control system for fare and baggage transportation, as well as a revenue control system;

4) there is no system for monitoring compliance by drivers with the road traffic regulations;

5) there is no control system for illegal carriers on commercial routes;

6) many commercial routes are served by rolling stock that is not designed to operate on regular city passenger transport routes;

7) illegal carriers travel on popular utility routes in cars;

8 ) the system of commercial routes is quite complex due to the fragmentation of some routes;

9) there is a fairly good division of spheres between public and commercial transport, duplication of routes between them is minimized;

10) the density of the city route network is quite high; transport accessibility is ensured in almost all remote micro districts [8].

The following directions can be singled out as prospects for the development of the system of city passenger transport, the interaction of transport operators with authorities and among themselves:

1) empowerment and creation of new departments responsible for working with transport operators and monitoring their work;

2) formation of a unified system of relations between authorities and public and commercial transport operators;

3) refinement of the route network of the city in order to divide routes into several categories and distribute types of the rolling stock;

4) introduction of a unified tariff policy, revenue control system and expansion of fare payment options;

5) introduction of a dispatching system using GPS / GLONASS on all routes of city public transport. 
The refinement of the route network of the city is necessary in order to minimize duplication of routes, determine the required types of the rolling stock along routes. It is also necessary to determine the required rolling stock depending on the passenger flow on the route and the capacity of the streets. In the future, it is possible to create a route network in which buses of small and especially small capacity will carry passengers from micro districts to certain nodal points at which they will be transferred to high-capacity vehicles. This will reduce the number of the rolling stock along the main streets while maintaining the quality of public transport services. To implement this option, it is necessary to provide territories for the construction of mini bus stations at these nodal points.

Thus, a positive effect can be achieved:

1) the optimal route network structure;

2) the uniform distribution of social load on different transport operators;

3) reduction of operating costs for the rolling stock maintenance;

4) increase of the transparency of the fare payment system and, accordingly, increase of the profitability of enterprises;

5) increase of safety during transportation;

6) clear scheduling of the rolling stock, observing intervals and schedules $[9,10]$.

\section{$4 \quad$ Route network optimization of the city passenger transport based on macroscopic modeling}

Based on the passenger traffic survey data, a load rating of the city's public transport network routes is compiled based on the number of passengers transported per day, passenger traffic on routes by traffic directions (direct / reverse), stopping points, and also time of day. Upon receipt of the final result, it is necessary that all routes and stopping points meet the requirements of both road safety and cost-effectiveness and economic efficiency. Since the problem under consideration is multi criteria, the following optimization criteria are proposed:

- the optimized route scheme being developed should be based on the existing stopping network; if possible, use existing turnarounds and if necessary, new turnarounds can be used;

- the existing route network can be changed to minimize the dissatisfaction of citizens using public transport daily;

- to improve the quality of public services, the bulk of passengers should be transported by vehicles of larger capacity, for which it is necessary to replace minibuses (the number of passengers carried - 13) with larger minibuses (with the number of passengers transported $18+4)$, medium and large buses that will be equipped places for transportation of people with limited mobility (this replacement of the rolling stock on certain routes will reduce the number of vehicles used by up to $30 \%$, thereby improve not only the capacity of the road network, but also the environmental issues of the city);

- it is necessary to use the principle of least duplication of routes; zonal route planning should ensure direct access from a zone to any other one;

- it is necessary to reduce the number of routes in the city due to the larger share of passengers transported by medium and large-capacity vehicles, including the use of new generation minibuses on certain routes;

- the pendulum migration characteristic of the city in the morning and evening, which was revealed during the study of the passenger flows of the route network, should be smoothed out by introducing scheduling based on GLONASS / GPS technologies not used in the city. 
To carry out work, a transport macro model of the city is developed using PTV Vision ${ }^{\circledR}$ software, while the macro model parameters must be configured to perform the tasks stipulated by the project requirements.

To solve the problems of modeling and optimizing the route network of the city, an information model is being built that reflects with the greatest possible accuracy the real processes that occur during the transportation of the city population. Such a model, due to the huge number of factors affecting the transportation process, includes several smaller models in terms of volume and content: transport network model (TN column), interdistrict correspondence matrix formation model, route network formation model (RN column) [11].

After building the model, it is necessary to conduct a study and analysis of its compliance with the real process of traffic. To carry out such a study, it is necessary to obtain the input data (parameters of the movement of vehicles, the interval of generation of vehicles, static parameters of the transport network, the phase intervals of traffic lights, the correspondence matrix) and the output data (average waiting time of vehicles, average queue lengths at intersections). Thus, the creation of the correspondence matrix of the studied transport network model is an important point when modeling traffic flows. It is necessary to obtain statistics on the demand of different regions during the day, during the week and during various annual seasons. This data can be obtained in various ways: using statistical surveys, analysis of the use of public transport, using cameras and various sensors installed on the road network. Based on the modeling of an improved route network, one can change the intervals of the passenger transport, reduce the number of duplicate routes, replace the rolling stock and abolish, extend or make changes to existing routes, etc [12].

\section{Determination of quality standards for the provision of services}

The quality of city passenger traffic is determined by a set of indicators characterizing the level of satisfaction of passenger needs for transport services. The main indicators of the quality of passenger transportation include:

- ride comfort (bus direction and regularity of their movement on routes);

- the time spent by passengers on movement (density of the transport network, the speed of movement, the required number of buses on the route, transfers, etc.);

- transportation safety;

- courtesy of the staff;

- severity of traffic accidents.

The conditions determining these indicators are:

- bus network density,

- bus frequency and interval,

- bus regularity on routes,

- the state of information and advertising about the operation of passenger transport.

Quality standards include:

1. Bus filling;

2. Bus filling ratio;

3. Regularity of movement;

4. Route network density;

5. Oriented standards for the rolling stock per $1 \mathrm{~km}$ of the route network during rush hours;

6. Oriented bus intervals;

7. Shift (transfer) coefficient);

8. The availability of at least two bus control points on city routes; 
9. Travel time;

10. Average travel distance, $\mathrm{km}$;

11. The average distance to the stop, $\mathrm{m}$;

12. Travel speed;

13. Travel frequency;

14. Comfort;

15. Rolling stock;

16. The level of passenger information services is determined by how much passengers are informed about the cost, duration, route pattern and changes in the movement of vehicles;

17. Safety.

Further consideration of proposals for improving the system as a whole and planning a development strategy may be based on such indicators as:

- Route frequency;

- The rolling stock per $1 \mathrm{~km}$ of the route network during rush hours;

- Passenger information service level;

- Social acceptability and tariff stability;

- Travel regularity;

- Compliance with comfort standards;

- Vehicles full of passengers [13].

\section{Implementation of the GLONASS or GLONASS I GPS navigation monitoring system in the field of passenger transportation}

Today, satellite transport monitoring systems function in many countries. Satellite monitoring of vehicles and fuel metering have become an urgent need for the normal functioning of transport, both in urban infrastructure and in a single enterprise. The implementation of this system, using modern satellite technologies, allows reducing transportation costs and increasing the efficiency of using vehicles. The satellite transport monitoring system using data from the GLONASS system justifies the costs of its installation and operation for a period of 3 to 9 months, by reducing the total cost of maintaining the rolling stock to $30 \%$.

For better provision of public services, it is proposed to introduce a GLONASS or GLONASS / GPS monitoring navigation system in the field of passenger transportation.

As part of the implementation of a GLONASS or GLONASS / GPS navigation monitoring system, it is necessary:

a) to create a Central Dispatch Service for the regulation of public transport, such as the Regional Navigation and Information Center (RNIC), whose purpose is:

information and navigation support for the activities of any road transport,

efficient vehicle traffic management;

improving the safety of passengers, special, dangerous, heavy and bulky goods;

effective implementation of control and supervisory powers in the transport complex.

RNIC is designed for information and navigation support of any automobile transport using GLONASS or GLONASS / GPS monitoring tools and having a unified platform of navigation applications and an information security system. It should provide ready-made solutions in the field of navigation activity for various sectors of the regional economy, individual selection, sale, installation, maintenance of navigation-related and additional equipment, information for customers in the field of navigation activity. This center will be 
engaged in the collection, storage, processing and transmission of monitoring information for various vehicles;

b) to equip all vehicles with a panic button to provide additional safety for passengers. The button can be installed in the immediate vicinity of the driver's seat or on the vehicle control panel, which will allow the driver to immediately report a dangerous situation to the competent authorities without attracting the attention of intruders. In an emergency, the driver must press a button and an alarm will immediately be sent to the control center console, and the GLONASS navigation system sensor will determine the location of the bus. The dispatcher will contact the special services and call them to the site;

c) to create an Internet portal where all vehicles involved in organizing transportation along a particular route will be displayed in real time with the possibility of predicting their arrival at a particular stopping point;

d) to place electronic information boards in the locations of social facilities at the stopping points, which predict in real time the arrival time of passenger route transport;

e) to create systems for monitoring the regularity of public transport movement for its optimal and more efficient operation $[14,15]$.

\section{$7 \quad$ Implementation of a Security Monitoring and Management System for mobile objects (Locatrans)}

Modern large MTCs in cities face a lot of problems, such as: coordination of various services, management and control of the equipment, traffic control, improving the quality of public transport services and security issues.

To solve the above problems, a Security Monitoring and Management System is proposed for moving objects (Locatrans). Such a system will allow for centralized control and management of enterprise mobile objects.

The monitoring system for mobile objects makes possible to determine the location of objects and display them on an electronic map; determine and display the parameters of the movement of objects: speed, direction of movement, the route traveled, places and duration of stops; monitor the status of sensors installed on a mobile object; remotely control actuators installed on a mobile facility; control the route of movement; receive timely notification of entry or exit from specified geographical areas; use the built-in standard reports; generate reports on various indicators for any period of time and create archives about the movement of objects and events that happened to them.

Using the Locatrans system, one can increase the volume of traffic and the number of services provided, reduce the accident rate, extend the life of vehicles, increase the staff discipline, exclude inappropriate use of transport, optimize fuel and GSM consumption and reduce the number of idle runs of vehicles.

The proposed system includes special hardware and software solutions that allow monitoring and operational management of special services, continuous monitoring of transport enterprises and organizations, to ensure personal safety [16].

\section{Implementation of the state automated information system "ERA-GLONASS"}

To ensure prompt transmission of a message about a vehicle during a traffic accident to emergency operational services in an automatic mode, in order to reduce the consequences of causing serious harm to human life and health as a result of a traffic accident and to reduce the time for information to be transmitted to emergency operational services, technical regulations requirements are established for the mandatory equipping of issued 
vehicles with a device (system) for calling emergency response services. The State Automated Information System "ERA-GLONASS" was created and put into commercial operation in the Russian Federation on January 1, 2015. The main goal of creating "ERAGLONASS" is to reduce the time it takes for emergency information to be delivered to emergency services. According to experts, the system will annually save about 4 thousand people by reducing the response time to accidents.

When "ERA-GLONASS" is generated in a case of a traffic accident, a message is transmitted via wireless channels in a call prioritization mode through a network of telecom operators, depending on whose signal is currently stable. The average information delivery time is about 10 seconds. If the communication signal of none of the presented operators is unstable, the generated data packet will be delivered to the address by SMS message. And when an additional module is connected, it will be possible to transmit a message through satellite communication. The signal enters the "ERA-GLONASS" system, and then it is sent to the dispatching service or the duty unit to organize the response of emergency operational services [17].

\section{Implementation of an information system on the time of arrival of the vehicle and on the degree of its filling up according to the information boards installed at the stopping points}

To improve the quality of CPPT services, the following information system is proposed. The proposed modernization of the information support system for public passenger transport allows passengers to receive information not only about the time of arrival of the vehicle at the stopping point, but also about the degree of occupancy of the vehicle. This feature of the system provides a passenger with a choice of a vehicle with minimal occupancy, for more comfortable travel, as a result, the distribution of passengers between vehicles occurs more evenly. For the city, this system provides an increase in the safety of the transportation process by reducing the "race for passengers" between carriers.

This scheme involves the installation of equipment that reads the number of passengers entering and leaving a vehicle. It involves the use of infrared sensors that produce automated passenger counting. The error in calculating the total number of passengers entering and leaving during one trip is $4 \ldots 7 \%$, depending on the vehicle content.

The data received from the equipment on the rolling stock carry information on the number of passengers in the vehicle.

Information is transmitted via GSM / GPRS networks to the control center, from where it is sent to the information board at the stopping points and to the website for monitoring passenger transport. The information board contains information about the route number, departure point, arrival time and availability of seats in the vehicle. The availability of seats is indicated on the scoreboard in the form of signals of different colors: green means the availability of free seats; yellow - the presence of standing places and the lack of landing; red - full vehicle load.

Thanks to the introduction of this system, it will be possible to track the number of passengers in public transport automatically. Timetables and route networks will be optimized. This system will reduce the number of trips during the "off-rush" time while maintaining the current level of quality of transport services. Reducing the need for vehicles during rush hours by eliminating less busy routes. The improvement of the route network is possible both by changing existing routes and introducing new ones, including shortened, express or ring ones, where significant local passenger flows are observed. 
It is important to emphasize that the presence of such a monitoring system makes possible to switch to a more flexible routing and system of schedules that take into account seasonality and other features of passenger flows. As a separate indicator of increasing the efficiency of the transportation process from the introduction of this technology, it is worth noting the effect of obtaining complex information about the actual load of the vehicle, i.e. information about how many passengers during which periods of time and on which sections of the route network a specific vehicle carries. This information, obtained daily for each vehicle, contributes to the full measurement of actual volumes of transport work, performance indicators of route network elements and the formation of a list of corrective indicators to account for fuel consumption depending on the vehicle capacity and highspeed modes of its movement.

The vehicles capacity depends on the behavior of passengers. In the absence of information about the time of arrival and the availability of seats in the rolling stock, passengers often make a choice in favor of the first one that coincides with their route. Because of this, there is an uneven distribution of passengers in vehicles. If passengers have such information at the stopping points, the distribution will become more uniform and the ease of using the transport will increase [18].

\section{Conclusion}

The city transport development strategy was developed in the form of a set of analytical studies revealing the problems of functioning of the passenger transport system, the constructed stratification levels of the system, each of which has its own list of existing problems. To solve existing problems, it is necessary to develop projects and implement monitoring systems. The improvement of existing and the creation of new city route systems, as well as the development of the passenger transport, can significantly improve the quality of services provided to the population. The results of the passenger flow survey make it possible to establish the characteristics of supply and demand for passenger transportation, the ability to calibrate a digital model of the route system of the city, make calculations of the passenger flow intensities in the morning rush hours, reduce or replace the rolling stock, and develop updated route patterns. The proposed measures to improve the quality of passenger service will allow regulating the movement of public transport using the GLONASS system, will provide centralized control and management of the company's mobile objects (Locatrans), reducing the time of accident notification to emergency services of "ERA-GLONASS", and will allow passengers to receive information not only about the time of arrival of the vehicle at the stopping point, but also about the degree of the vehicle capacity.

\section{References}

1. K.P. Andreev, V.V. Terentyev World of Transport 15 No 6 (73) 156-161 (2017)

2. Sh.M. Musakozhoev, M.S. Kachkynaliev Economic Bulletin 1 58-82. (2018)

3. I.E. Agureev, V.A. Mityugin Problems of the study of systems and means of automobile transport 1, 26-34 (2019)

4. V.A. Mityugin, S.A. Volkov, A.Yu. Kharabadzhi Alternative energy sources in transport and technological complex: problems and prospects of rational use 2 No 2 , 797-802 (2015)

5. V.A. Pyshny Izvestia of Tula State University. Technical science 5-1, 23-30 (2015)

6. Sh.M. Musakozhoev, M.S. Kachkynaliev, Economic Bulletin 2, 34-77, (2018) 
7. S.A. Shiryaev, O.S. Kodilenko, A.S. Kodilenko Young scientist 7, 218-221, (2016)

8. K.A. Tashbaeva, D.A. Osmonalieva Young scientist 15, 326-330 (2016)

9. V.V. Lanskykh, P.P. Volodkin, TOSU Science Notes 4 No 4, 1465-1473 (2013)

10. Final report of Overview Japan International Cooperation Agency (JICA) (2013)

11. K.P. Andreev, V.V. Terentyev Transport Information Bulletin 9 (267) 21-23 (2017)

12. S.N. Boyarsky, R.N. Kovalev, V.A. Kuznetsov Innovative transport 1 (27) 12-15 (2018)

13. M.I. Razzakov Science and new technologies, No 4, 60-63. (2013)

14. A.V. Kurdinova, A.G. Strugovets, I.A. Shikhaleva. The youth. Society. Modern science, technology and innovation 13 30-31. (2013)

15. A.R. Bekboyev, K.B. Arykbaev Herald of KSUSTA 4, 58-61 (2013)

16. I.M. Popova, A.P. Belikov, E.A. Popova, Bulletin of the Saratov State Technical University T 2 No 2 (71) 344-347 (2013)

17. S.V. Dorokhin, V.V. Terentyev, K.P. Andreev The world of transport and technological machines 2 (57) 67-73 (2017)

18. G.G. Denisov, I.A. Shkarpova Road transport of the Far East 1, 134-138 (2014) 